\title{
Sphincter Saving Surgery in Locally Advanced Low Rectal Cancer after Neoadjuvant Chemoradiotherapy
}

\author{
ISMAIEL A. MOURAD, M.D.*; HISHAM A. EL-HOSSIENY, M.D.**; ABDEL-HAMID H. EZZAT, M.D.*; \\ IHAB S. HUSSEIN, M.D.*; MOHAMMAD T. FOUAD, M.Sc.* and RASHA M. ALLAM, M.D.*** \\ The Departments of Surgical Oncology*, Radiation Therapy** and Biostatistics \& Cancer Epidemiology***, \\ National Cancer Institute, Cairo University, Egypt
}

\begin{abstract}
Aim: To evaluate the feasibility of sphincter saving surgery in locally advanced low rectal cancer after neoadjuvant concomitant chemoradiotherapy (CCRT) by assessing the effect of CCRT on downstaging of primary tumor, hence sphincter preservation rate and outcome.

Patients and Methods: Patients presenting to the National Cancer Institute-Cairo University from May 2014 to October 2014; with locally advanced low (3-6m from the anal verge) rectal cancer received long-course CCRT and the response was evaluated, then they were subjected to APR or sphincter saving surgery.

Results: The study started by 60 patients; 33/60 (55\%) underwent APR, 25/60 (41.7\%) underwent sphincter saving surgery and $2 / 60$ patients (3.3\%) lost follow-up.

The clinical response was assessed by the status of the distance from the anal verge: It increasedin 23/60 patients $(38.33 \%)$, stationary in $17 / 60$ patients $(28.33 \%)$ and decreasedin $20 / 60$ patients. The radiological response showed: downstaging occurred in $27 / 60(45 \%)$. Pathological response revealed: Down-staging in $28 / 58$ patients $(48.3 \%)$.

Negative distal margin was obtained in all patients had sphincter saving surgery with one case only had positive radial margin.

Conclusion: Sphincter saving surgery is an oncologically safe alternative to the standard APR in low rectal cancer, with the added benefit of avoiding a permenant stoma. The use of preoperative concomitant chemoradiotherapy (CCRT) enhances the rate of sphincter saving surgery by downsizing and downstaging of the tumors.
\end{abstract}

Key Words: Low rectal cancer - Sphincter saving surgery Neoadjuvant chemoradiotherapy.

\section{Introduction}

THERE has been an evolution in the treatment of rectal cancer in recent times. A few decades ago,

\footnotetext{
Correspondence to: Dr. Ismaiel A. Mourad E-mail: mohammed.taher@nci.cu.edu.eg mohamed.taher@,57357.org
}

rectal cancer treatment was solely a surgical endeavor. Nowadays, it has evolved into therapy involving several disciplines. Nevertheless, surgery remains the cornerstone of curative treatment [1]

Although Miles' abdominoperineal resection is the "gold standard" for the treatment of low rectal neoplasms [2]; (which means a permenant colostomy), restorative resection may now be possible with equivalent oncologic disease control and survival [3].

Advances in surgical technique with the use of either advanced stapling or manual coloanal anastomoses have allowed for achieving continuity of the gastrointestinal tract at levels closer to the anal verge than those achieved historically [1]

The advent of adjuvant and neoadjuvant chemoradiotherapy has also increased local control of disease [4] and in some instances has led to increased survival [1].

Neoadjuvant (preoperative) concomitant chemoradiotherapy (CCRT) has become a standard treatment of locally advanced rectal adenocarcinomas. The clinical stages II (cT3-4, N0, M0) and III (cT1-4, N+, M0) [5]

Neoadjuvant CCRT is effective in reducing local recurrence. It is associated with tumor downstaging, hence increases the rate of sphincter saving surgery $\&$ tumor resectability [5] .

In the $1980 \mathrm{~s}$, a distal margin of $5 \mathrm{~cm}$ was required. In the ensuing decades, the " 2 -cm-rule" was accepted and adopted [6]. This rule has been challenged, however, and currently there are some who suggest that a distal margin of $1 \mathrm{~cm}$ is appropriate for optimal oncologic outcome [7]. This 
provides a greater proportion of rectal cancer patients with the possibility of sphincter preservation $[8]$.

Recently, adequacy of the circumferential resection margin is being considered of greater importance in the risk of local recurrence of rectal cancer [9].

The oncologic and functional outcomes of sphincter saving resection low rectal cancer were revolutionized by two developments: Recognition of the importance of the mesorectum in the spread of rectal cancer and the appreciation of the necessity to replace the reservoir function of the resected rectum [10].

\section{Patients and Methods}

This prospective study has been conducted at the National Cancer Institute (NCI), Cairo University, Egypt.

All the patients attended the outpatient clinic within 6 months during the period from May 2014 to October 2014 and diagnosed with low rectal cancer (extraperitoneal) with clinical stages II (cT3-4, N0, M0) and III (cT1-4, N+, M0) "i.e. those who needed to receive neoadjuvant treatment "were assessed according to the following inclusion and exclusion criteria.

\section{Inclusion criteria:}

- Low rectal cancer: Distal tumor edge within 3$6 \mathrm{~cm}$ from the anal verge.

- Disease stage: Stage II (cT3-4, N0, M0) and stage III (cT1-4, N+, M0).

- Satisfactory preoperative sphincter function and continence.

\section{Exclusion criteria:}

- Unsatisfactory preoperative sphincter function and continence.

- Disease stage: Stage I (cT1-2, N0, M0) and stage IV (metastatic; M1).

Revaluation of the patients was done after the end of neoadjuvant CCRT to identify those who considered candidates for sphincter saving surgery versus those who didn't according to the following mentioned indications and contraindications of sphincter saving surgery.

\section{Indications of sphincter saving surgery:}

- Low rectal tumors: With distal tumor edge at a distance ranging from $3 \mathrm{~cm}$ or more (after CCRT) from the anal verge.
- Local spread restricted to rectal wall or internal anal sphincter (IAS) (i.e. T2).

- Satisfactory preoperative sphincter function and continence.

Contraindications sphincter saving surgery:

- T4 lesions (tumors invading the visceral peritoneum or adjacent organs or structures).

- Unsatisfactory preoperative sphincter function and continence.

- Tumors invading the external anal sphincter (EAS) (i.e. T3).

- Tumors with distal edge from the anal verge $<3 \mathrm{~cm}$, or those whose distal edge from the anal verge has decreased despite neoadjuvant CCRT.

Accordingly, patients were categorized preoperatively as follows:

a- Cases which satisfied the indications of sphincter saving surgery (25/60).

b- Those didn't satisfy the indications of sphincter saving surgery underwent APR (33/60).

c- Two cases didn't do any surgery (One developed metastasis and one refused surgery then both lost follow-up).

\section{- Preoperative concomitant chemoradiotherapy (CCRT):}

Radiotherapy: Radiotherapy was performed usinga 3D technique, treatment volume included the rectum, the whole mesorectum and the draining lymph node chains to a dose of $50.4 \mathrm{~Gy}$ over 28 fractions over 5 weeks (180cGy per fraction).

Chemotherapy: The preoperative concomitant chemotherapy was administered as Capecitabine $850 \mathrm{mg}$ every 12 hours daily 5 days per week concomitantly with radiotherapy.

\section{- Surgical Technique:}

Surgery was done after an interval period of about 6-8 weeks after the end of chemoradiation allowing the maximum response of CCRT to be obtained.

\section{- Pathology of the surgical specimen:}

We followed the pathological reports of the surgical specimens to aid us in assessment of CCRT response and in the comparisons between sphincter saving surgery and APR.

\section{Statistical analysis:}

Data were analyzed using SPSS win statistical package version 23 Numerical data were expressed 
as mean and standard deviation (SD), median, or range as appropriate. Qualitative data were expressed as frequency and percentage. Chi-square (Fisher's exact) test was used to examine the relation between qualitative variables to test for proportion independence as appropriate.

Paired comparisons of categorical variables were done by McNemar's test as appropriate. Paired comparisons of numerical variables were done by paired Student $t$ test as appropriate. Testing for normality was checked by Shapiro-Wilk test of normality and the Kolmogorov-Smirnov test of normality.

Comparison between groups to test for group effect with respect to numerical variables was done using Mann-Whitney U-test for 2 groups and Kruskal Wallis test for more than 2 groups. Comparison between different time periods within each group was tested for time effect with respect to numerical variables was done using Wilcoxon matched pairs sign rank test for 2 time periods and Freidman test that was followed by post hoc pair wise comparison by Wilcoxon matched pairs sign rank test if needed for more than 2 time periods.

Correlation analysis was done using Pearson correlation tests. Kaplan-Meier analysis was used to illustrate the effect of surgery type and surgical margin on each of survival, local recurrence and metastasis.

$p$-value $\leq 0.05$ was considered significant and every test was 2 tailed.

\section{Results}

The study was conducted on 60 patients. All of them received preoperative (neoadjuvant) concomitant chemoradiotherapy (CCRT). Reevaluation was done and eligibility for type of surgery was determined as discussed in the previous section.

Thirty-three out of the 60 patients $(55 \%)$ underwent APR, 25/60 (41.7\%) underwent sphincter saving surgery and $2 / 60$ patients $(3.3 \%)$ lost followup.

\section{Patients and tumor characteristics:}

The demographic and clinical data collected on the studied group (60) are illustrated in Table $(1 \mathrm{a}, \mathrm{b})$.
Table (1A): Demographic and clinical data of all patients.

\begin{tabular}{|c|c|}
\hline Demographic and clinical data & $\begin{array}{l}\text { Study sample } \\
\text { Mean } \pm \text { SD }\end{array}$ \\
\hline Age (years) & $43.03 \pm 14.03$ \\
\hline $\begin{array}{l}\text { Distance from anal verge } \\
\text { before treatment }(\mathrm{cm})\end{array}$ & $4.1 \pm 0.896$ \\
\hline Interval before treatment (days) & $50.97 \pm 3.26$ \\
\hline \multicolumn{2}{|c|}{ Table (1B): Demographic and clinical data of all patients. } \\
\hline Demographic and clinical data & $\begin{array}{l}\text { Study sample } \\
(\mathrm{n}=60)(100 \%)\end{array}$ \\
\hline \multicolumn{2}{|l|}{ Sex: } \\
\hline Female n $(\%)$ & $35(58.3)$ \\
\hline Male $\quad \mathrm{n}(\%)$ & $25(41.7)$ \\
\hline \multicolumn{2}{|l|}{ Grade: } \\
\hline $\mathrm{I} \quad \mathrm{n}(\%)$ & $1(1.7)$ \\
\hline II n (\%) & $39(65)$ \\
\hline III n (\%) & $20(33.33)$ \\
\hline \multicolumn{2}{|l|}{ Tumor stage: } \\
\hline Stage II n $(\%)$ & $18(30)$ \\
\hline Stage III n $(\%)$ & $42(70)$ \\
\hline \multicolumn{2}{|l|}{ Radiological T: } \\
\hline $\mathrm{T} 2$ n $(\%)$ & $2(3.3)$ \\
\hline $\mathrm{T} 3 \mathrm{n}(\%)$ & $58(96.7)$ \\
\hline \multicolumn{2}{|l|}{ Radiological $N$ : } \\
\hline N0 n $(\%)$ & $18(30)$ \\
\hline N1 n (\%) & $23(38.3)$ \\
\hline $\mathrm{N} 2 \mathrm{n}(\%)$ & $19(31.7)$ \\
\hline
\end{tabular}

Effect of preoperative concomitant chemoradiotherapy (CCRT):

Descriptive results of clinical, radiological and pathological effects of CCRT are illustrated in the following tables.

Table (2): Presentation of the effect of preoperative CCRT on all patients.

\begin{tabular}{|c|c|}
\hline Therapy data & $\begin{array}{l}\text { Study sample } \\
(\mathrm{n}=60)(100 \%)\end{array}$ \\
\hline $\begin{array}{l}\text { Distance from anal verge } \\
\text { after treatment }(\mathrm{cm}) \text { : } \\
\quad \text { Mean } \pm \mathrm{SD}\end{array}$ & $4.18 \pm 1.41$ \\
\hline $\begin{array}{l}\text { Type of surgery: } \\
\text { Abdominoperineal resection } \\
\text { (APR) n (\%) } \\
\text { Sphincter saving surgery n (\%) } \\
\text { Didn't do surgery n }(\%)\end{array}$ & $\begin{array}{l}33(55) \\
25(41.7) \\
2(3.3)\end{array}$ \\
\hline $\begin{array}{l}\text { Surgical margin*: } \\
\text { Positive n }(\%) \\
\text { Negative } \mathrm{n}(\%)\end{array}$ & $\begin{array}{l}4 / 58(6.9) \\
{[3 \text { radial, } 1 \text { distal }]} \\
54 / 58(93.1)\end{array}$ \\
\hline $\begin{array}{l}\text { Free distal margin }(\mathrm{cm}): \\
\text { Mean } \pm \mathrm{SD} \text { (range) }\end{array}$ & $2.36 \pm 1.24(0.3-5)$ \\
\hline $\begin{array}{l}\text { Free Radial margin }(\mathrm{cm}) \text { : } \\
\text { Mean } \pm \text { SD (range) }\end{array}$ & $1.34 \pm 1.07(0.1-5)$ \\
\hline
\end{tabular}




\section{A- Clinical response:}

By digital rectal examination (DRE) and proctoscopy, the distance from the lower edge of the tumor to the anal verge was increased (i.e. tumor regression) in $23 / 60$ patients $(38.33 \%)$, stationary in $17 / 60$ patients $(28.33 \%)$ and was decreased (i.e. tumor progression) in 20/60 patients (33. 33\%). Thus sphincter sparing procedures could be performed in 25/60 patients (i.e. $41.7 \%$ ).

The study patients who were classically candidates for APR were rendered 33 (55\%), 2 of them actually were clinically free, but underwent APR for the debate on the 'watch and wait policy'.

Table (3): Pretreatment vs posttreatment tumor characteristics in all patients.

\begin{tabular}{|c|c|c|c|}
\hline $\begin{array}{l}\text { Effect of } \\
\text { therapy data }\end{array}$ & $\begin{array}{l}\text { Before treatm } \\
(\mathrm{n}=60) \\
(100 \%)\end{array}$ & $\begin{array}{l}\text { After treatment } \\
\qquad(\mathrm{n}=60) \\
(100 \%)\end{array}$ & $\begin{array}{l}p^{*} \\
\text { value }\end{array}$ \\
\hline \multicolumn{4}{|c|}{$\begin{array}{l}\text { Distance from anal } \\
\text { verge }(\mathrm{cm}) \text { : }\end{array}$} \\
\hline Mean \pm SD & $4.1 \pm 0.896$ & $4.18 \pm 1.41$ & 0.597 \\
\hline \multicolumn{4}{|c|}{ Radiological T: } \\
\hline T0 n (\%) & $0(0)$ & $2(3.3)$ & 0.001 \\
\hline T1 n (\%) & $0(0)$ & $1(1.7)$ & \\
\hline T2 n (\%) & $2(3.3)$ & $33(55)$ & \\
\hline T3 n (\%) & $58(96.7)$ & $24(40)$ & \\
\hline \multicolumn{4}{|c|}{ Radiological N: } \\
\hline N0 n (\%) & $18(30)$ & $34(56.7)$ & 0.001 \\
\hline N1 n (\%) & $23(38.3)$ & $17(28.3)$ & \\
\hline N2 n (\%) & $19(31.7)$ & $9(15)$ & \\
\hline \multirow{2}{*}{\multicolumn{4}{|c|}{$\begin{array}{l}\text { Radiological } T v s . \\
\text { Pathological } T^{* *}\end{array}$}} \\
\hline & & & \\
\hline T0 n (\%) & $0(0)$ & $3(5.2)$ & 0.043 \\
\hline T1 n (\%) & $0(0)$ & $2(3.4)$ & \\
\hline T2 n (\%) & $2(3.3)$ & $15(25.9)$ & \\
\hline T3 n (\%) & $58(96.7)$ & $35(60.3)$ & \\
\hline T4 n (\%) & $0(0)$ & $3(5.2)$ & \\
\hline \multicolumn{4}{|c|}{$\begin{array}{l}\text { Radiological } N v s . \\
\text { Pathological } N^{* * * *}\end{array}$} \\
\hline $\begin{array}{l}\text { Pathological } \\
\text { N0 n }(\%)\end{array}$ & & & 0.001 \\
\hline N1 n $(\%)$ & $\begin{array}{l}18(30) \\
23(38.3)\end{array}$ & $\begin{array}{l}33(58.9) \\
12(21.4)\end{array}$ & 0.001 \\
\hline N2 n $(\%)$ & $19(31.7)$ & $11(19.6)$ & \\
\hline
\end{tabular}

However, there was no significant statistical difference in the tumor distance from anal verge before and after treatment $(p>0.05)$, mean of the distance between tumor and anal verge was 4.1 $\mathrm{cm}$ initially and $4.18 \mathrm{~cm}$ after therapy.

\section{B- Radiological response:}

Overall tumor staging, the study started by $18 / 60(30 \%)$ stage II and 42/60 (70\%) stage III. After CCRT the radiological staging showed: Downstaging occurred in 27/60 (45\%), upstaging occurred in $2 / 60(3.3 \%)$ and stationary staging in $31 / 60(51.7 \%)$.

The tumor stage after CCRT was as follows: Stage I: $21 / 60$ (35\%), stage II: $11 / 60(18.3 \%)$, stage III: $26 / 60(43.3 \%)$ and two patients $(3.3 \%)$ had complete response.

\section{C- Pathological response:}

The comparison of the pretreatment stage (clinical+radiological) with the pathological stage, showed:

The study started by $18 / 60$ (30\%) stage II and $42 / 60$ (70\%) stage III. The pathological stage was as follows: Stage I: $13 / 58$ (22.4\%), stage II: $18 / 58$ (31\%), stage III: $23 / 58(39.7 \%)$ and complete response (i.e. no viable tumor): $2 / 58(3.4 \%)$. The stage could not be assessed in 2 patients (no lymph nodes were retrieved).

Down-staging was found in $28 / 58$ patients $(48.3 \%)$, up-staging occurred in $4 / 58$ patients $(6.9 \%)$ and no change occurred in $24 / 58$ patients (41.4\%). In 2 patients (3.4\%), the stage could not be assessed.

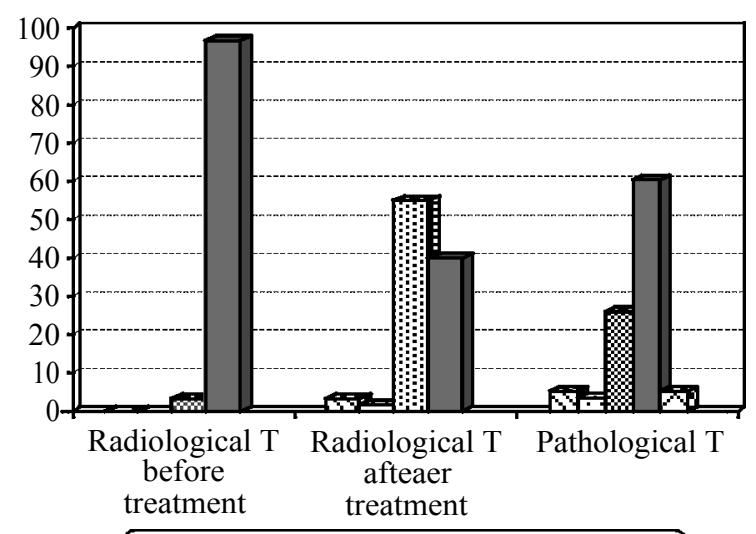

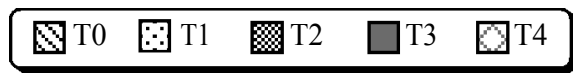

Fig. (1): Therapy effect on percentages of Radiological and pathological $\mathrm{T}$ in the studied patients.

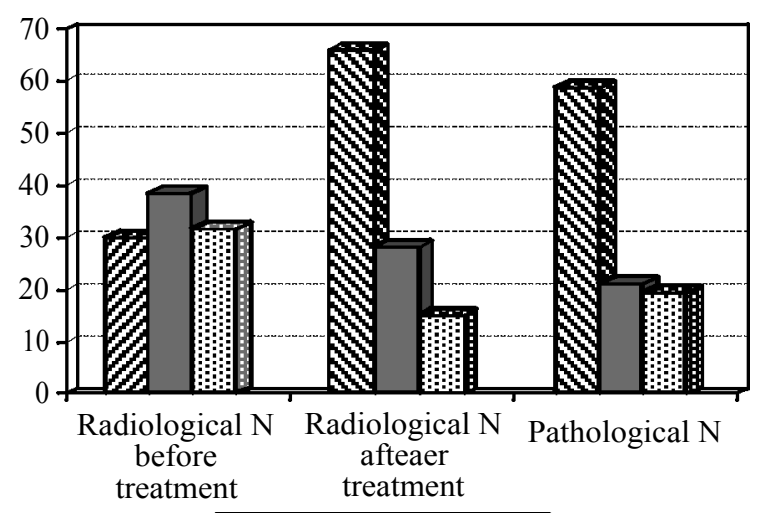

图N0 $\square \mathrm{N} 1 \quad$ 耳in2

Fig. (2): Therapy effect on percentages of Radiological and pathological $\mathrm{N}$ in the studied patients. 


\section{Oncological outcomes:}

\section{1-Surgical margin:}

In the Sphincter saving group: Negative distal margin was obtained in all patients. One case had positive radial margin $(<1 \mathrm{~mm})$ in one patient $(4.8 \%)$.

In those underwent APR, the distal margin was positive in one patient (3\%) and the radial margin was positive in 2 patients $(6 \%)$.

The means and ranges of the free margins were comparable between the SSR patients and the APR patients.

\section{2- Local recurrence, metastasis and survival:}

N.B. we document this from a descriptive point of view, as it has no statistical significance because of the short follow-up period; The mean followup period was $14.95 \pm 3.11$; range: (3-18 months).

- Eight patients had local recurrence (13.79\%): Five in the APR group and 3 in the sphincter saving surgery group.

- Four patients developed distant metastasis (6.9\%): Three in the APR group and one case in the sphincter saving surgery group.

-The mean time for local recurrence and for distant metastasis was 9.26 months (3-16) and 11 months (6-16) respectively.

- Four patients died of the disease (6.9\%), weather directly or indirectly: $3(5.2 \%)$ in the APR group and those died of metastasis; and $1(1.7 \%)$ in the sphincter saving surgery group and this patient died from malabsorption, dehydration and renal failure as a complication of colostomy.

- The mean time of death was 9.75 months (6-14).

\section{Discussion}

In recent years, the indication for an abdominoperineal resection could be narrowed. Today, the operation should be considered only in cases where the tumor infiltrates the sphincter apparatus, and in a pre-existing severe sphincteric insufficiency [11].

So, an oncologically safe alternatives of APR surgery and accordingly a permenant stoma is to be considered. Sphincter saving surgery on these basis is considered a safe procedure [11].

The use of preoperative concomitant chemoradiotherapy (CCRT) had made it possible to treat very low rectal tumors by sphincter-sparing that would previously have needed abdominoperineal resection [5].

In a study conducted by Bai and his colleagues aimed to verify the effects of preoperative chemoradiotherapy in controlling local recurrence and improving sphincter saving surgey rate, they had the following results:

Clinical and pathological response. The clinical responses in terms of tumor downsizing was recorded according to the percentage of reduction in the product of the two perpendicular diameters of the primary tumor. The clinical response rate was $83.5 \%$. Complete regression of the rectal tumor was observed in 12 patients $(14.1 \%)$. Twenty-four patients $(28.2 \%)$ had a reduc-tion of $>50 \%$ and 35 patients $(41.2 \%)$ had a reduction of $>30 \%$. No tumor progression was found [12].

The pathological response: Surgical specimens without microscopic disease were obtained with TME and margin-free resection for all 85 patients [12] .

Overall downstaging of the T classification was achieved in 64 patients (75.3\%). Pathological complete response was found in 13 patients $(15.3 \%)$. T1 disease was observed in 18 patients $(21.2 \%)$ and T2 in 33 patients (38.8\%). Twentyone patients $(24.7 \%)$ remained T3 pathologically [12].

Valentin and his colleagues in their study had 10 patients with ultra-low rectal cancer were managed in this study by multimodality treatment. Preoperative CCRT was applied to six T3-4 staged patients, and this treatment enhanced tumor shrinkage more than $25 \%$ in five patients; and they found that no residual cancer was identified in 2 patients among these 5 patients [13].

Salem and his colleagues conducted their study where neoadjuvant chemoradiation was administrated for all patients. Pathological evaluation of the resected specimen show all circumferential resection margins were clear by at least $1 \mathrm{~cm}$, complete clinical and pathological response in 3 patients (6\%), and complete clinical response with only microscopically residual carcinoma in 20 patients $(41 \%)$, partial response in 18 patients (36.7\%), no significant response in 8 patients $(16 \%)$ [14] .

In our study, we found the clinical response as follows: The distance from the lower edge of the tumor to the anal verge was increased (i.e. tumor 
regression) in $23 / 60$ patients ( $38.33 \%$ ), stationary in $17 / 60$ patients $(28.33 \%)$ and was decreased (i.e. tumor progression) in $20 / 60$ patients $(33.33 \%)$. Thus sphincter sparing procedures could be performed in 25/60 patients (i.e. 41.7\%): 21/60 (35\%) ISR \& 4/60 (6.7\%) LAR.

Regarding the radiological response, we found that after CCRT radiological downstaging occurred in $27 / 60(45 \%)$.

By assessing the pathological response, we found that down-staging occurred in 28/58 patients $(48.3 \%)$.

The differences in the numbers and percentages in the different studies; including our study is most likely related to the different parameters used to assess the response.

Conclusion: Sphincter saving surgery is an oncologically safe alternative to the standard APR in low rectal cancer, with the added benefit of avoiding a permenantstoma. The use of preoperative concomitant chemoradiotherapy (CCRT) enhances the rate of sphincter saving surgery by downsizing and downstaging of the tumors.

\section{References}

1- SPANOS C.P. and P.C.: Intersphincteric Resection for Low Rectal Cancer: An Overview. International Journal of Surgical Oncology, 2012.

2- MILES E.W.: The Radical Abdomino-perineal operation for cancer of the rectum and of the pelvic colon. British Medical Journal, pp. 1-43, 1990.

3- RICCIARDI R., et al.: The Status of Radical Proctectomy and Sphincter-Sparing Surgery in the United States.
Diseases of the Colon. \& Rectum., 50 (8): pp. 1119-1127, 2007.

4- SAUER R., et al.: Preoperative versus postoperative chemoradiotherapy for rectal cancer. The New England Journal of Medicine, 351 (17): pp. 1731-1740, 2004

5- MARTIJNSE I.S., et al.: T3+ and T4 rectal cancer patients seem to benefit from the addition of oxaliplatin to the neoadjuvant chemoradiation regimen. Annals of Surgical Oncology, 19 (2): pp. 392-401, 2012.

6- SCHIESSEL R., et al.: Technique and long-term results of intersphincteric resection for low rectal cancer. Diseases of the Colon. and Rectum, 48 (10): pp. 1858-1865, 2005.

7- BUJKO K., et al.: Is the 1-cm Rule of Distal Bowe Resection Margin in Rectal Cancer Based on Clinical Evidence? A Systematic Review. Annals of Surgical Oncology, 19 (3): pp. 801-808, 2012.

8- KIRAN R.P., LIAN L. and LAVERY I.C.: Does a subcentimeter distal resection margin adversely influence oncologic outcomes in patients with rectal cancer undergoing restorative proctectomy?, Diseases of the Colon and Rectum., 54 (2): pp. 157-163, 2011.

9- QUIRKE P., et al.: Local Recurrence of Rectal Adenocarcinoma Due To Inadequate Surgical Resection. The Lancet, 328 (8514): pp. 996-999, 1986.

10- KEIGHLEY M.R.B. and WILLIAMS N.S. : Surgery of the anus, rectum \& amp; colon, Elsevier Saunders, 2008.

11- SCHLAG P.M.: Surgical Sphincter Preservation in Rectal Cancer. The Oncologist, 1: 288-92, 1996.

12- BAI X., et al.: Sphincter-preserving surgery after preoperative radiochemotherapy for T3 low rectal cancers. Oncology Letters, 3 (6): pp. 1336-1340, 2012.

13-VALENTIN L.I., et al.: Clinical outcome of intersphincteric resection for ultra-low rectal cancer. Journal of IMAB Annual Proceeding (Scientific Papers), 18 (1): pp. 226230, 2012

14- SALEM M.A.E., et al.: Sphincter Saving Surgeries for Locally Advanced Low Rectal Cancer after Neoadjuvant Chemoradiation. Journal of Cancer Therapy, (4): pp. 1228-1235, 2013. 


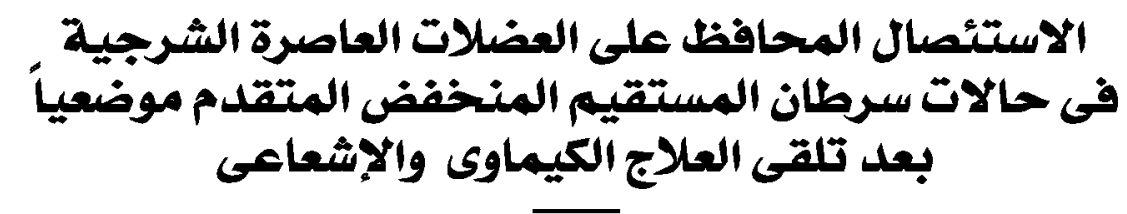

الهدف: تقييم إمكانية استخدام الجراحات المحافظة على العضلات العاصرة الشرجية لاستئصال سرطان المستقيم المنخفض والمتقدم

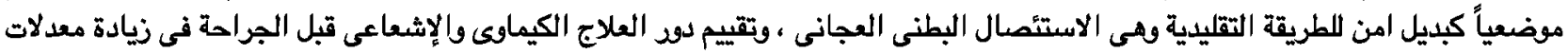

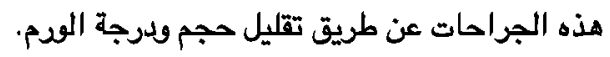

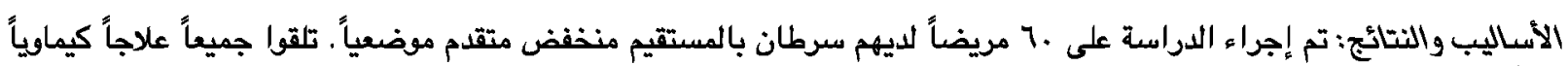

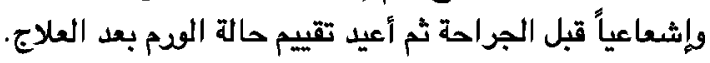

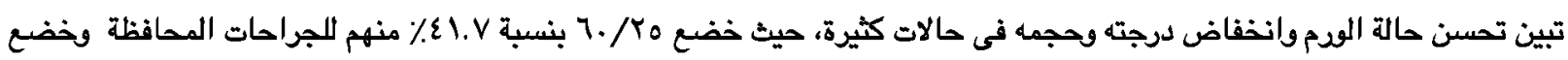

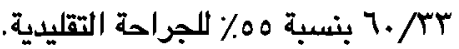

وكانت نتائج الجراحات المحافظة مقارية من ناحية الأمان الوظيفية ونسب الإرتجاع والإنتشار للطريقة الجراحية التقليدية. الخلاصة: الجراحات المحافظة على العضلات العاصرة الشرجية بديل امن لجراحة الاستئصال البطن العجانى التقليدية فى سرطان

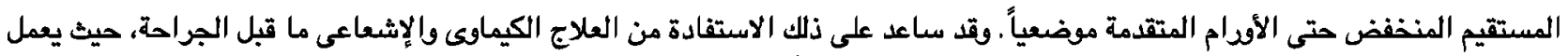

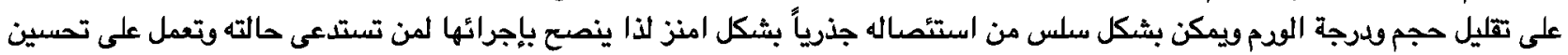

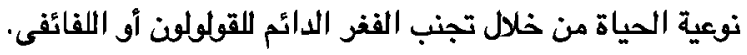

